\title{
REKAYASA ULANG DONGKRAK REL KERETA API KAPASITAS 10 TON
}

\author{
RE-ENGINEERING OF RAIL JACK CAPACITY 10 TON
}

\author{
Surasno, Budi Tjahjohartoto \\ Balai Besar Bahan dan Barang Teknik, Jl. Sangkuriang No.14 Bandung 40135 \\ Email: surasno2005@yahoo.co.id
}

Diterima: 4 November 2014 Diperbaiki: 26 November 2014 Disetujui: 22 Desember 2014

\begin{abstract}
ABSTRAK
Dongkrak rel mekanik dengan daya angkat 10 ton dan tinggi ungkit 5-10 cm yang digunakan oleh PT. KAI life time-nya relatif pendek dan cepat rusak. Dari failure analysis yang telah dilakukan terhadap dongkrak yang rusak,menunjukkan bahwa rusak atau tidak berfungsinya dongkrak rel disebabkan oleh patah (gompal) pada rack gear pengangkat yang diawali korosi pada rangka bagian dalam, bushing, rack gear pengangkat, poros pinion, dan spline utama. Komponen ini menipis, bidang kontak gigi menjadi longgar dan menerima beban dinamik siklik sehingga terjadilah patah. Untuk meningkatkan kualitas dongkrak rel telah dilakukan rekayasa ulang dengan mengganti spesifikasi bahan komponen terutama yang mempunyai bidang kontak seperti rack gear pengangkat, roda gigi, poros pinion, spline utama, bushing dan tumpuan. Bahan logam baja untuk komponen dongkrak rel dipilih dari baja perkakas AISI 4043 (DIN 1.6511-34NiCrMo6), DIN 1.2510 (100MnCrW4) dan baja karbon umum (St. 37 dan St. 42) dengan heat treatment yang tepat. Selanjutnya dilakukan modifikasi desain sudut rack gear pengangkat dari 5 derajat menjadi 20 derajat. Hasil uji tekan beban 5 dan 10 ton menunjukkan hasil yang baik, tidak terjadi perubahan bentuk dan memenuhi persyaratan teknis PT. KAI.
\end{abstract}

Kata kunci: dongkrak rel, analisis kegagalan, rekayasa ulang, sudut rack gear, heat treatment

\begin{abstract}
Mechanical rail jack with capacity of 10 tons and high leverage of 50-10 cm which is used by PT. KAI have a relatively short lifetime and easily damaged. On the damage rail jack or that does not function has been done failure analysis, which showed that the rails jack damaged or malfunction caused by a broken (chipped) on the lifting rack gear that corrosion initiated at inside parts of the frame, bushing, rack gear lifter, pinion shaft, and the main spline. This component becomes thin, the contact area on the teeth become loose and receive dynamic cyclic load then fracture occurs. To improve the quality of rail jack, reengineering was done by replacing the metal specifications of components, especially components that have contact areas such as lifting rack gear, gear, pinion shaft, the main spline, bushing and pedestal. Steel metal metals for the components of the rail jack were selected from tool steel AISI 4043 (DIN 1.6511-34NiCrMo6), DIN 1.2510 (100MnCrW4) and common carbon steel (St. 37 and St. 42) with appropriate heat treatment. Furthermore, modification was made on lifting angle of gear-rack from 5 degree to 20 degree. The pressure test on 5 and 10 ton loads show good results, no changes in shape and meet the technical requirements of the PT. KAI.
\end{abstract}

Keywords: rail jack, failure analysis, re-engineering, angle of rack gear, heat treatment

\section{PENDAHULUAN}

Pada saat ini kebutuhan masyarakat terhadap sarana transportasi sangat tinggi. Kereta api sebagai salah satu alternatif sarana transportasi, memiliki keunggulan kompetitif jika dibandingkan dengan jenis kendaraan transportasi yang lain, khususnya angkutan darat untuk jarak sedang dan jarak jauh. Untuk sekali beroperasi, kereta api dapat mengangkut ratusan penumpang ataupun puluhan ton barang dengan biaya relatif murah.

Untuk mengantisipasi peningkatan kebutuhan masyarakat akan sarana transportasi masal, pemerintah mendorong PT. KAI (PT. Kereta Api Indonesia) agar meningkatkan 
pelayanan, frekuensi perjalanan, dan membangun trek ganda (double track). Rel kereta api yang dimiliki oleh PT.KAI panjangnya ribuan kilometer (sekitar $6000 \mathrm{~km}$ ) terbentang di antara kota-kota di pulau Jawa dan sebagian pulau Sumatera. Rel kereta api yang setiap satuannya mempunyai panjang 33-39 feet atau sekitar 10-12 m, ketika disambung-sambung dengan cara pengelasan (continous welded rail) dapat mencapai $1 \mathrm{~km}$ pada trek lurus sehingga pada waktu perbaikan dan perawatan, rel kereta api memerlukan suatu alat bantu yang disebut dongkrak rel.

Dongkrak rel kereta api adalah suatu konstruksi peralatan yang berfungsi untuk mengangkat atau mengungkit rel ketika melesak turun. Alat ini harus mampu mengangkat hingga beban 10 ton. Ketika dongkrak rel dilepas dari dudukan rel walaupun dengan cara dipukul tidak boleh mengalami deformasi atau perubahan bentuk yang dapat menyebabkan tidak berfungsinya peralatan ini. Alat ini harus mudah dipakai oleh teknisi, sehingga desainnya harus sederhana dan ringan, harus kuat terhadap beban dinamik tidak boleh terjadi patah, retak dan longgar pada dudukan poros. Terutama di bagianbagian kritis harus mampu menahan beban dinamik. Dongkrak rel yang banyak dipakai untuk sarana pemeliharaan rel jalan lintasan kereta api adalah jenis dongkrak (jack) ungkit mekanik, umumnya di lapangan dikatakan sebagai dongkrak kodok karena menyerupai kodok. Kekuatan dongkrak ini mampu mengangkat beban seberat 10 ton.

Selama ini masih ada kendala yang dihadapi oleh PT. KAI dalam penggunaan dongkrak rel yaitu umur pakainya pendek dan beban di bawah 10 ton.Banyak kerusakan pada rack gear, gigi pinion korosi, aus dan pecah (gompal). Selain life time (umur pakai) pendek, cara penggunaan oleh teknisi yang kurang tepat dapat menyebabkan cepat rusak. Seperti ketika kondisi darurat melepas dongkrak rel kadangkadang dilakukan secara paksa dengan pukulan, karena alasan kereta api akan segera melewati jalur tersebut. Life time dongkrak rel pada umumnya $1 \mathrm{~s} / \mathrm{d} 3$ tahun atau bahkan lebih pendek tergantung pada frekuensi pemakaian dongkrak di lintasan padat atau rendah. Asal produk merek luar negeri berbahasa mandarin buatan China. Dongkrak ini digunakan oleh PT. KAI Divisi Regional II Sumatera Barat di Padang. Kebutuhan dongkrak di Divisi regional II Padang rata-rata 43 buah dalam satu tahun. Dongkrak jenis ini disukai oleh operator karena praktis dan ringan. Pemakaian dongkrak ini sangat sering yaitu hampir setiap hari dengan lima hari dalam seminggu.

Diprediksi hingga 10 tahun ke depan pemeliharaan sarana jalan kereta api masih menggunakan dongkrak rel karena merupakan pekerjaan padat karya di Indonesia. Faktor pendukung keberhasilan adalah kekuatan industri kecil yang mampu meningkatkan penguasaan teknologi pengolahan metal baja. Walaupun saat ini peluang pasar dongkrak rel sebatas perkeretaapian akan tetapi kecenderungan akan meningkat signifikan karena pertumbuhan transportasi penggunaan kereta api di Indonesia semakin meningkat.

Dari hasil penelitian analisis kegagalan pada dongkrak yang rusak dan tidak berfungsi menunjukkan bahwa dongkrak rel patah (gompal) pada rack gear pengangkat yang diawali korosi pada rangka bagian dalam, bushing, rack gear pengangkat, poros pinion, dan spline utama. Proses korosi dan kehausan pada komponen ini akan menipis, bidang kontak gigi menjadi longgar dan ketika menerima beban dinamik siklik sehingga terjadi patah. Dari penelitian analisis kegagalan perlu dilakukan perubahan spesifikasi bahan komponen terutama komponen yang mempunyai bidang kontak diganti dengan spesifikasi bahan yang lebih baik.

Perekayasaan ini dilakukan atas dasar dari hasil analisis kegagalan,selanjutnya melakukan re-engineering dongkrak rel kereta api. Tujuannya adalah untuk menghasilkan dongkrak rel yang memenuhi spesifikasi desain teknis sederhana yang unggul dan mudah dikerjakan melalui pemilihan bahan yang lebih baik, optimalisasi desain manufaktur serta proses perlakuan panas. Alasan lain adalah berdasarkan prediksi bahwa pertambahan sarana dan prasarana moda angkutan kereta api di-proyeksikan dari tahun ke tahun akan meningkat, hal ini berpengaruh pada kebutuhan dongkrak rel di PT. KAI dan merupakan peluang bagi industri kecil. Juga keterkaitan program Kementerian Perindustrian untuk pengembangan riset terapan pada penelitian dan perekayasaan teknologi untuk industri kecil dalam meningkatkan pengetahuan bahan-bahan logam, desain, proses pembuatan dan perlakuan panas pada logam baja perkakas. 


\section{BAHAN DAN METODE}

Bahan komponen dongkrak mekanik dibuat dari baja kontruksi umum general carbon steel St.37 dan St.42 untuk bagian kerangkanya. Bagian utama yang menahan beban berat akan dibuat dari bahan baja perkakas DIN 1.2510, sedangkan untuk poros, pinion dan roda gigi dari bahan DIN 1.6511. Jumlah komponen dongkrak ada 54 buah. Bagian utama yakni lidah gear rack berfungsi langsung untuk mengangkat rel beban maksimum 10 ton (Gambar 1). Pengangkatan beban menggunakan sistem gerakan perputaran roda-roda gigi dengan cara bertahap dan paling ujung gerakan lengan dongkrak dengan beban ringan $1 \mathrm{~s} / \mathrm{d} 2 \mathrm{~kg}$.



Gambar 1. Dongkrak Rel Kereta Api

Metal DIN 1.2510 adalah metal cold work tool steel atau baja perkakas dan memiliki komposisi kimia (dalam persen): 0,85 C; 0,25 Si; 1,10 Mn; 0,55 Cr; 0,10 V dan 0,55 W. Baja perkakas ini biasanya digunakan untuk perkakasperkakas potong (dies dan punch), perkakas blanking dan punching, Perkakas untuk pembuatan ulir, perkakas untuk perkayuan, mesin-mesin potong kayu, kertas dan industri pengerjaan logam, alat-alat ukur, dan moulds plastik. Kekerasan yang dapat diperoleh untuk baja perkakas dari metal DIN 1.2510 ini adalah 63-65 HRC.

Metal DIN 1.6511 adalah metal yang dibuat oleh Bohler yang merupakan machinery steels atau baja permesinan. Kekerasan yang dapat diperoleh untuk baja pemesinan dari metal DIN 1.6511 ini adalah 54-57 HRC. Bahan ini biasanya digunakan untuk komponen yang mengalami tekanan yang sangat tinggi dengan beban berat seperti pesawat terbang, otomotif dan rekayasa mekanik seperti: poros-poros propeller (propeller shafts), poros-poros penghubung (connecting rods), poros-poros roda gigi (gear shafts), crankshafts, dan komponen-komponen landing gear, heavy forging: seperti rotors, shafts dan discs.

Cara kerja pemakaian dongkrak rel di lapangan adalah dengan menempatkan lidah rack gear pengangkat tepat di bawah rel pada empat posisi, 2 buah sebelah kiri dan 2 buah sebelah kanan pada jalur rel yang sama (Gambar 3). Masing-masing diberi jarak sekitar 4 balok landasan. Rack gear pengangkat dongkrak dinaikkan menggunakan tangkai lengan tuas operator secara bersamaan oleh 4 operator sampai ketinggian lidah rack gear pengangkat mencapai tinggi tertentu biasanya $2 \mathrm{~s} / \mathrm{d} 5 \mathrm{~cm}$. Permukaan rel harus sejajar dan diukur menggunakan waterpass. Kekosongan bagian dudukan rel diisi balast yang dimasukkan ke celah bawah bantalan hingga padat. Gigi ungkit dilepas sehingga rack gear pengangkat dongkrak turun dari dudukan relnya dan dongkrak mudah dilepas.

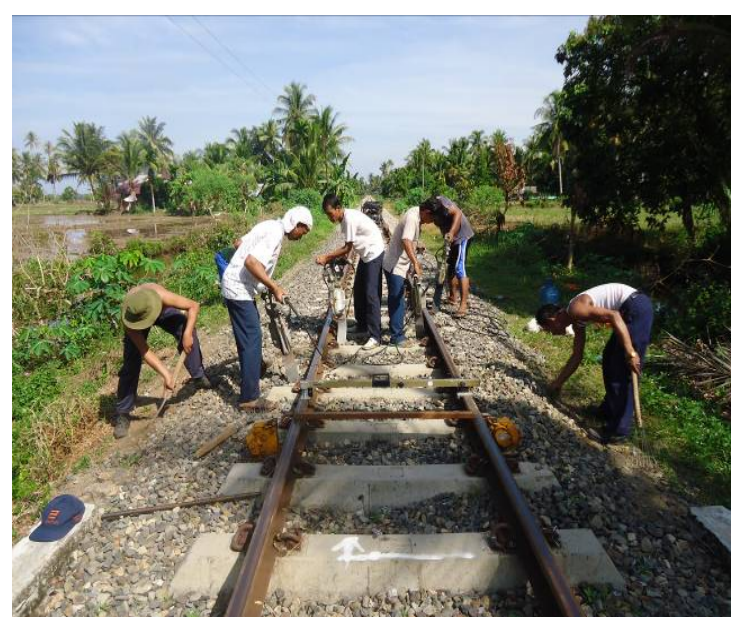

Gambar 2. Pemakaian Dongkrak Rel

Metode rekayasa ulang (re-engineering) yang diterapkan dalam penelitian ini adalah dengan melakukan perhitungan yang berhubungan dengan rancangan kesesuaian antara kekuatan struktur, komponen dan faktor keamanan. Selanjutnya dilakukan proses manufaktur, yaitu pemilihan bahan atau kesesuaian bahan yang digunakan, proses pembuatan, heat treatment, pengelasan, pemasangan atau perakitan dan pengujian di laboratorium. Yang 
dimaksud dengan rekayasa ulang dalam tulisan ini adalah melakukan evaluasi existing dongkrak atau rekayasa baru (pemilihan metal baru \& modifikasi sudut rack gear pengangkat), dan dilaksanakan dengan cara:

1. Mempelajari existing dongkrak mulai dari mengurai komponen, mengukur dimensi dan menggambar ulang berdasarkan dimensi dan geometri setiap komponen.

2. Mempelajari cara kerja komponen dengan cara menyusun ulang seluruh komponen sampai menjadi utuh kembali, menjadi sebuah produk dongkrak dalam bentuk gambar tiga dimensi.

3. Menghitung ulang tegangan-tegangan yang bekerja pada komponen dengan cara perhitungan terbalik berdasarkan gaya luar sebagai beban awal ditentukan dari beban yang ditetapkan 10 ton yang ditanggung oleh komponen yang berhubungan langsung.

4. Memilih dan menentukan bahan baja perkakas berdasarkan hasil perhitungan gaya, tegangan yang bekerja di komponen. Perhitungan kekuatan berdasarkan pada komponen utama rack gear pengangkat karena menanggung beban yang paling berat.

5. Proses manufaktur (pemesinan, pengelasan, heat treatment dan perakitan).

6. Modifikasi komponen yang menurut hitungan tidak cukup kuat untuk menahan beban/tegangan kerja. Modifikasi sudut rack gear pengangkat dari 5 derajat menjadi 20 derajat.
Perhitungan ulang hanya dilakukan pada komponen kritis oleh beban pada rack gear pengangkat. Sedangkan untuk komponen tidak kritis: pinion, roda gigi, tuas pengunci dinding rangka, landasan, tuas pengungkit, pedal dan pegas-pegas tidak dilakukan perhitungan ulang karena dinilai kekuatannya sudah memadai.

\section{HASIL DAN PEMBAHASAN}

\section{Perhitungan Kekuatan Rack Gear Pengangkat}

Beban luar akibat beban rel ditetapkan sebesar 10 ton atau 10.000 kgf. Beban luar tersebut diterima oleh permukaan atas rack gear pengangkat atau tuas pengangkat dan diteruskan ke rack gear pengangkat. Dimensi dan geometri rack gear pengangkat adalah: lebar $\mathrm{w}=41 \mathrm{~mm}$, tinggi $\mathrm{h}=10 \mathrm{~mm}$, sudut kemiringan $\alpha=5^{\circ}$ dan tinggi kontak antar gigi $\mathrm{h}_{1}=7 \mathrm{~mm}$. Perhitungan kekuatan rack gear adalah sebagai berikut:

Luas bidang kontak $=\left(30 / \sin 85^{\circ}\right) \times 7=211 \mathrm{~mm}^{2}$ Gaya kontak $(\mathrm{F}), \quad=10.000 \mathrm{kgf}$

Tegangan kontak $=10.000 \mathrm{kgf} / 211 \mathrm{~mm} 2$

$$
=47,39 \mathrm{kgf} / \mathrm{mm}^{2}
$$

Faktor keamanan $\quad=1,5$

Kekuatan bahan $\quad=47,39 \times 1,5=71,09 \mathrm{~kg} / \mathrm{mm}^{2}$

Jadi bahan yang digunakan untuk rack gear pengangkat dongkrak minimum harus mempunyai kekuatan, $\boldsymbol{\sigma}=\mathbf{7 1 , 0 9} \mathrm{kgf} / \mathrm{mm}^{2}$.
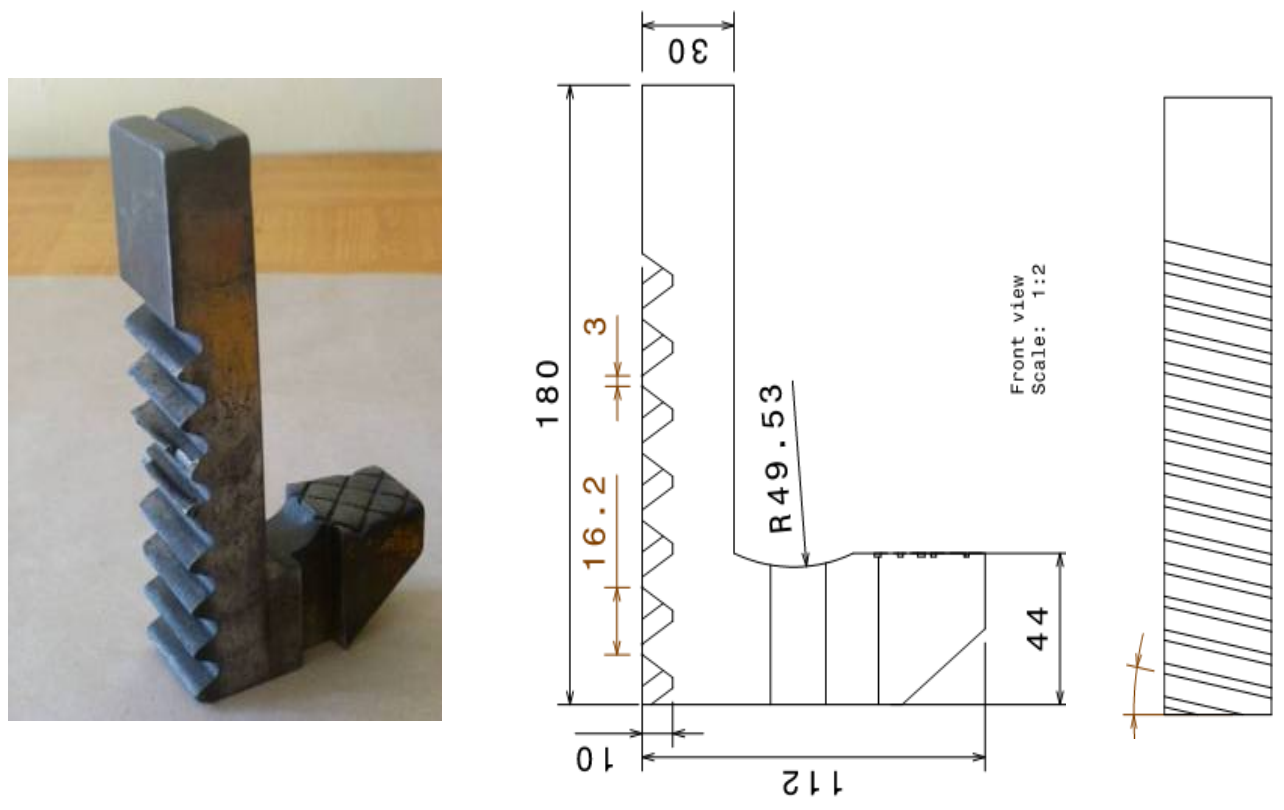

Gambar 3. Rack Gear 
Tabel 1. Karakteristik Bahan Komponen

\begin{tabular}{ll}
\hline \multicolumn{1}{c}{ Kondisi Operasi } & \multicolumn{1}{c}{ Karakteristik Bahan } \\
\hline Mampu menahan beban hingga 10.000 kgf & Minimum kekuatan, $\boldsymbol{\sigma}=\mathbf{7 1 , 0 9} \mathrm{kgf} / \mathrm{mm}^{2}$ \\
Tahanan gesekan antara gigi dengan pinion & Permukaan rack gear harus keras \\
Tahanan gesek antara rack dengan liner & Permukaan body rack harus halus \\
Kebutuhan produk dalam jumlah banyak & Relatif murah dan tersedia di dalam negeri \\
\hline
\end{tabular}

Pemilihan bahan rack gear dilakukan berdasarkan pada kondisi operasi dongkrak dan persyaratan karakteristik bahan yang digunakan untuk dongkrak. Kondisi operasi dan karakteristik untuk pemilihan bahan rack gear berdasarkan pertimbangan sebagaimana pada Tabel 1. Bahan rack gear yang memenuhi syarat diantaranya adalah bahan sekelas AISI-4340, dalam hal ini dipilih bahan dari DIN 1.2510.

Perhitungan ulang untuk menentukan kekuatan rack gear dilakukan pada sudut 5, 10, 15 dan 20 derajat menggunakan cara perhitungan seperti di atas dan hasilnya dapat dilihat pada Tabel 2. Keempat desain dengan sudut rack gear tersebut menunjukkan bahwa kekuatan bahan lebih kecil dari nilai tensile strength bahan amotit $\left(138 \mathrm{kgf} / \mathrm{mm}^{2}\right)$ sehingga desain kontruksi dengan sudut tersebut bisa dikatakan baik. Setelah dibandingkan dari keempat pemilihan sudut rack gear tersebut, maka yang paling baik adalah sudut rack gear $20^{\circ}$. Rack gear ini menerima beban paling rendah $67,144 \mathrm{~kg} / \mathrm{mm}^{2}$.

Tabel 2 Pemilihan Sudut Rack Gear

\begin{tabular}{cc}
\hline $\begin{array}{c}\text { Sudut } \\
\text { (derajat) }\end{array}$ & $\begin{array}{c}\text { Kekuatan minimum, } \\
\sigma, \mathrm{kgf} / \mathrm{mm}^{2}\end{array}$ \\
\hline 5 & 71.09 \\
10 & 70,35 \\
15 & 69,00 \\
20 & 67,144 \\
\hline
\end{tabular}

\section{Pembuatan Komponen Dongkrak Rel}

Proses manufaktur yang dilaksanakan adalah sebagai berikut: proses pemilihan bahan (Tabel 3), proses pembuatan komponen, proses perlakuan panas, proses pengelasan, dan proses pemasangan. Pembuatan 54 jenis komponen dongkrak rel (Lampiran 1) melalui proses pemesinan: memotong menggunakan mesin gergaji, membentuk bulat menggunakan mesin bubut, membentuk gigi menggunakan mesin bubut, membentuk rata permukaan menggunakan mesin skrap dan menghaluskan menggunakan mesin gerinda dan mesin poles.

Proses perlakuan panas (heat treatment) komponen yang dibuat dari bahan DIN 1.2510 dan DIN 1.6511. Metode perlakuan panas sebagai berikut: komponen dipanaskan di dalam tungku hingga suhu mencapai $900^{\circ} \mathrm{C}$ ditahan selama 30 menit (holding time), dicelup pada media oli, diangkat, setelah dingin diuji kekerasannya dan nilai kekerasan rata-rata 60 HRC. Proses pengerasan dilakukan pada 26 buah komponen sbb: rack gear pengangkat, roda gigi (lurus, miring, bintang, roda gigi pengungkit), poros pinion, spline utama, ring stopper, poros baut, spacer, bantalan pinion, bantalan, spline, pena spline. Setelah proses perlakuan panas selesai kemudian dilakukan proses blackenning untuk memberi tampakan komponen warna hitam.

Proses pengelasan dilakukan pada bagian: slider blok pada rangka kanan dan rangka kiri, part sisi rack pada rangka kanan dan rangka kiri, rakitan spline pada spline depan dan pena spline depan, rakitan tuas pembebas, tuas pembebas pedal, pin tuas pembebas 1 , pin tuas pembebas 2 dan pelat pembebas, rakitan rangka pengungkit: pelat pengungkit dan body pengungkit.

Proses pemasangan (assembly), kegiatan perakitan komponen dongkrak dibuat dalam 7 tahap kegiatan perakitan sebagai berikut: perakitan 1 merakit dongkrak komponen $1 \mathrm{~s} / \mathrm{d}$ 7, perakitan 2 merakit rangka kanan dan kiri serta komponen $11 \mathrm{~s} / \mathrm{d} 18$, perakitan 3 merakit spline komponen $21 \mathrm{~s} / \mathrm{d} 36$, perakitan 4 merakit tuas pembebas komponen $31 \mathrm{~s} / \mathrm{d}$ 36, perakitan 5 merakit rangka pengungkit komponen $41 \mathrm{~s} / \mathrm{d}$ 46, perakitan 6 merakit bracket penyangga komponen $51 \mathrm{~s} / \mathrm{d} 53$, perakitan 7 merakit spline depan komponen 61 s/d 63. 
Proses akhir (finishing): penghalusan permukaan menggunakan ampelas pada seluruh permukaan dan didempul, bagian yang cacat dilas (sedikit), pengecatan dasar warna abu-abu dan pengecatan akhir warna silver. Dongkrak hasil rekayasa ulang dengan rack gear pengangkat 5 dan 20 derajat dilihat pada Gambar 4.

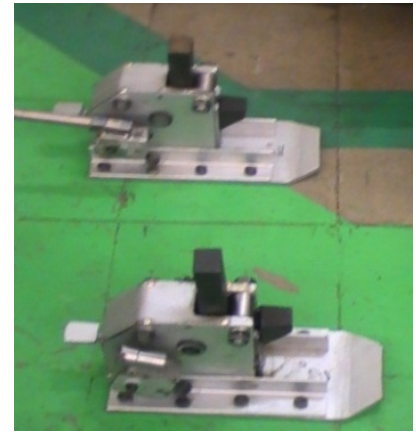

Gambar 4. Dongkrak Hasil Rekayasa Ulang

\section{Pengujian}

Pengujian dilaksanakan di Balai Besar Bahan dan Barang Teknik (Gambar 5), cara uji menggunakan mesin tekan beban 10 ton dengan beban bertahap 5 dan 10 ton. Hasil pengamatan adalah sebagai berikut:

1. Dongkrak rel sudut rack gear pengangkat 5 derajat, hasil uji baik, tidak ada perubahan bentuk atau tidak terjadi deformasi.

2. Dongkrak rel sudut rack gear pengangkat 20 derajat, hasil uji baik, tidak ada perubahan bentuk atau tidak terjadi deformasi. Pengujian unjuk kerja di lapangan belum dapat dilakukan karena harus ada izin dari PT. Kereta Api Indonesia.

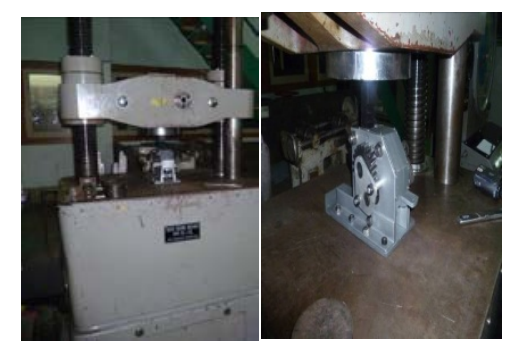

Gambar 5. Pengujian Tekan Dongkrak Hasil Re-Engineering

\section{Pengoperasian dan Perawatan}

Prosedur pemakaian harus dilaksanakan dengan benar agar dongkrak rel berumur panjang dan optimal. Untuk menghindari beban hentakan terhadap dongkrak ketika digunakan di lapangan maka harus dilakukan beberapa hal berikut:
1. Ketika dioperasikan harus ditempatkan pada posisi tegak lurus kearah beban rel, hindari kemungkinan miring karena dapat menyebabkan kerusakan gigi oleh beben tidak merata atau bidang tidak rata.

2. Pergerakan lengan pengungkit dilakukan dengan teratur.

3. Dongkrak rel tidak boleh dilepas paksa dengan pukulan keras.

Selanjutnya melaksanakan prosedur perawatan di lapangan dan perawatan di tempat penyimpanan dengan melakukan hal-hal sebagai berikut:

1. Pemeliharaan harian, memberikan pelumasan pada bagian bergerak dengan grease.

2. Perawatan mingguan, bilamana ditemukan bagian yang longgar pada pergerakan gigi atau baut, lakukan pengencangan.

Simpan di tempat kering yang tidak terkena air hujan.

\section{KESIMPULAN}

Perekayasaan ulang dongkrak rel kereta api dapat dilakukan dengan cara mengganti spesifikasi bahan komponen dongkrak lama (existing), kemudian melakukan pembuatan 63 komponen yang terdiri dari 26 komponen dibuat dari bahan baja perkakas AISI 4340 sekelas DIN 1.6511 dan DIN 1.2510 yang digunakan untuk komponen utama antara lain: rack gear pengangkat, poros pinion, spline utama dan komponen lainnya. Komponen yang dibuat dari baja perkakas ini sudah melalui proses heat treatment yaitu proses pengerasan seluruhnya (full hardening). Tiga puluh tujuh (37) komponen dibuat dari bahan baja umum sekelas St. 37 dan St 42 untuk komponen yang menerima beban ringan, komponen rangka, slider blok dll.

Modifikasi sudut gigi pengangkat rack gear dari 5 derajat menjadi 20 derajat. Merakit dua dongkrak rel dengan sudut rack gear 5 dan 20 derajat dengan spesifikasi komponen seperti tersebut di atas. Berdasarkan hasil pengujian statis dua dongkrak (rack gear 5 dan 20 derajat) di laboratorium dengan beban bertahap 5 dan 10 ton menunjukkan bahwa kedua dongkrak berfungsi dengan baik, tidak terjadi perubahan bentuk dan pergerakan gigi-gigi masing ringan dan lancar sehingga disimpulkan bahwa dongkrak hasil rekayasa ulang (re-engineering) dapat memenuhi spesifikasi yang ditetapkan oleh PT. KAI. 


\section{SARAN}

1. Untuk menjaga agar dongkrak dapat beroperasi sesuai fungsinya dan mempunyai life time yang panjang maka perlu disiapkan prosedur pemakaian dan pemeliharaan serta melaksanakannya secara.

2. Untuk perbaikan selanjutnya (continuous improvement) sudut rack gear pengangkat tidak perlu 20 derajat, disarankan cukup 10 derajat.

3. Semua komponen yang menggunakan bahan K 460 sebaiknya diganti dengan VCN karena sifat-sifat fisik (kekerasan dan modulus elastisitas) metal VCN sudah memadai dan diharapkan harga bahan-bahan komponen akan lebih ekonomis.

\section{DAFTAR PUSTAKA}

[1] ASM International Handbook Committee, Electronics File, 2002, ASM Handbook Volume 11, Failure Analysis and Prevention, ASM International, USA.
[2] ASM International Handbook Committee, Electronics File, 1999, ASM Handbook Volume 20, Metal Selection and Design, ASM International, USA.

[3] ASM International Handbook Committee, Electronics File, 2002, Metals Handbook Vol ume 4, Heat Treating, ASM International, USA.

[4] Carvill, J., 2003, Mechanical Engineer's Data Handbook, Butterworth Heinemann, Oxford, USA.

[5] Giachino, W. Weeks, G.S. Johnson, 1973, Welding technology, an atp Publication.

[6] Wiryosumarto, Harsono, 1996. Teknologi Pengelasan Logam, Pradnya Paramita.

[7] B.H. Amstead, Phillip F. Ostwald, Sriati Djaprie, 1995, Manufacturing Processes, Erlangga.

[8] George E. Dieter, 1988, Mechanical Metalulurgy, 3rd. edition,Erlangga.

[9] R.C. Hibbeler, 1986, Engineering Mechanics, 4th, Macmillan Publishing Company, USA

[10] Tata Surdia, Shinroku Saito, 1992, Pengetahuan Bahan Teknik, Pradnya Paramita 
Lampiran 1. Komponen Dongkrak Rel

\begin{tabular}{|c|c|c|c|c|c|}
\hline No & $\begin{array}{l}\text { No } \\
\text { Item }\end{array}$ & Nama Komponen & Qty & Spec & Dimensi \\
\hline 1 & 1 & Gigi rack pengangkat & 1 & DIN 1.2510 & $\neq 42 \times 200 \times 120$ \\
\hline 2 & 2 & Roda gigi miring & 1 & DIN 1.6511 & $\Phi 100 \times 50$ \\
\hline 3 & 3 & Roda gigi lurus & 1 & DIN 1.6511 & $\Phi 62 \times 20$ \\
\hline 4 & 4 & Poros pinion & 1 & DIN 1.2510 & $\Phi 42 \times 130$ \\
\hline 5 & 5 & Spline utama & 1 & DIN 1.2510 & Ф 36x115 \\
\hline 6 & 6 & Ring stopper R Gigi Lurus & 1 & DIN 1.2510 & $\Phi 30 \times 20$ \\
\hline 7 & 7 & Roller & 1 & St 42 & $\Phi 32 \times 50$ \\
\hline 8 & 11 & Rangka body R & 1 & ST 37 & $\llcorner 4 \times 40 \times 255$ \\
\hline 9 & 12 & Rangka body $\mathrm{L}$ & 1 & ST 37 & $\llcorner 4 \times 40 \times 255$ \\
\hline 10 & 13 & Rangka Landasan & 1 & ST 42 & $\neq 8 \times 160 \times 340$ \\
\hline 11 & 14 & Slider Blok & 2 & ST 42 & $\neq 16 \times 18 \times 130$ \\
\hline 12 & 15 & Rangka kanan 1 & 1 & ST 42 & $\neq 8 \times 180 \times 180$ \\
\hline 13 & 16 & Rangka kiri & 1 & ST 42 & $\neq 8 \times 180 \times 180$ \\
\hline 14 & $17 \mathrm{~A}$ & Poros baut tuas pembebas & 1 & DIN 1.6511 & $\Phi 20 \times 115$ \\
\hline 15 & 17B & Spacer & 1 & DIN 1.6511 & $\Phi 16 \times 60$ \\
\hline 16 & $17 \mathrm{C}$ & Pena penahan pegas & 1 & \begin{tabular}{|l|} 
ST 37 \\
\end{tabular} & $\Phi$ 10x75 \\
\hline 17 & 17D & Poros baut pelat rack & 1 & DIN 1.6511 & $\Phi 22 \times 125$ \\
\hline 18 & $17 \mathrm{E}$ & Pelat sisi rack & 2 & ST 37 & $\neq 6 \times 65 \times 42$ \\
\hline 19 & $17 \mathrm{~F}$ & Mur M16 & 2 & & Std com \\
\hline 20 & $17 \mathrm{G}$ & Mur M10 & 2 & & Std com \\
\hline 21 & $17 \mathrm{H}$ & Mur M14 & 4 & & Std com \\
\hline 22 & $18 \mathrm{~A}$ & Bantalan Pinion Kiri & 2 & DIN 1.2510 & $\Phi 55 \times 30$ \\
\hline 23 & $18 \mathrm{~B}$ & Bantalan Pinion Kanan & 1 & DIN 1.2510 & $\Phi 42 \times 30$ \\
\hline 24 & $18 \mathrm{C}$ & Bantalan Spline Kiri & 1 & DIN 1.2510 & $\Phi 42 \times 30$ \\
\hline 25 & $18 \mathrm{D}$ & Bantalan Spline Kanan & 1 & DIN 1.2510 & $\Phi 32 \times 30$ \\
\hline 26 & 21 & Plat Spline Depan & 2 & ST 42 & $\neq 8 \times 160 \times 90$ \\
\hline 27 & 22 & Penahan Spline Depan & 1 & DIN 1.2510 & $\neq 15 \times 20 \times 25$ \\
\hline 28 & 23 & Bantalan Spline Depan Kiri & 1 & DIN 1.2510 & $\Phi 30 \times 15$ \\
\hline 29 & 24 & Bantalan Spline Depan Kanan & 1 & DIN 1.2510 & $\Phi 32 \times 20$ \\
\hline 30 & 25 & Pena Spline Depan & 1 & DIN 1.6511 & $\Phi 13 \times 60$ \\
\hline 31 & 26 & Poros Baut. Spline Depan & 1 & DIN 1.6511 & $\Phi 18 \times 110$ \\
\hline 32 & $27 \mathrm{~A}$ & Pegas Spline A & 1 & Baja pegas & $\Phi 2-2,5$ \\
\hline 33 & $27 \mathrm{~B}$ & Pegas Spline B & 1 & Baja pegas & $\Phi 2-2,5$ \\
\hline 34 & 28 & Roda Gigi Spline Depan & 1 & DIN 1.6511 & $\Phi 55 \times 20$ \\
\hline 35 & 29 & Ring Plate Poros Spline Depan & 1 & DIN 1.6511 & $\Phi 28 \times 10$ \\
\hline 36 & 31 & Tuas Pembebas & 1 & ST 42 & $\neq 8 \times 100 \times 50$ \\
\hline 37 & 32 & Tuas Pembebas Pedal & 1 & ST 42 & $\neq 8 \times 120 \times 125$ \\
\hline 38 & 33 & Pin tuas Pembebas 1 & 1 & ST 42 & $\Phi 18 \times 45$ \\
\hline 39 & 34 & Pin tuas Pembebas 2 & 1 & ST 42 & $\Phi 20 \times 60$ \\
\hline 40 & 35 & Pelat Pembebas & 2 & ST 37 & $\neq 8 \times 20 \times 50$ \\
\hline 41 & 36 & Pegas Tuas Pembebas & 1 & Baja Pegas & $\Phi 2-\Phi 2,5$ \\
\hline 42 & 41 & Plat Pengungkit & 2 & ST 42 & $\neq 8 \times 55 \times 75$ \\
\hline 43 & 42 & Penahan & 1 & DIN 1.2510 & $\neq 16 \times 50 \times 30$ \\
\hline 44 & 43 & Bodi Pengungkit & 1 & \begin{tabular}{|l|} 
ST 42 \\
\end{tabular} & $\Phi 34 \times 60$ \\
\hline 45 & 44 & Tuas & 1 & ST 42 & $\Phi 22 \times 610$ \\
\hline 46 & 45 & Rd Gigi Pengungkit & 1 & DIN 1.6511 & $\Phi 50 \times 20$ \\
\hline 47 & 46 & Poros Pengungkit & 1 & ST 42 & $\Phi 10 \times 40$ \\
\hline 48 & 47 & Pegas Pengungkit & 1 & Baja per & $\Phi 2-\Phi 2,5$ \\
\hline 49 & 51 & Braket Penyangga & 1 & ST 42 & $\neq 8 \times 110 \times 110$ \\
\hline 50 & 52 & Bantalan Braket Pinion & 1 & DIN 1.2510 & $\Phi 35 \times 10$ \\
\hline 51 & 53 & Bantalan Braket Spline & 1 & DIN 1.2510 & $\Phi 32 \times 15$ \\
\hline 52 & 61 & Spline depan & 1 & DIN 1.2510 & $\Phi 32 \times 130$ \\
\hline 53 & 62 & Roda Gigi Bintang & 1 & DIN 1.6511 & $\Phi 40 \times 25$ \\
\hline 54 & 63 & Spie & 1 & S45C & $\neq 3 \times 25 \times 6$ \\
\hline
\end{tabular}

